\title{
Carcinoma of Male Breast in Association with the Klinefelter Syndrome
}

\author{
A. W. JACKSON,* M.B., CH.B., D.M.R.T. ; S. MULDAL, $\dagger$ CAND. REAL. (OSLO, LUND); C. H. OCKEY, $\dagger$ PH.D. ;
}

P. J. O'CONNOR, $†$ B.SC., PH.D.

Brit. med. F., 1965, 1, 223-225

Carcinoma of the male breast is a comparatively rare form of malignant-disease, representing about $0.2 \%$ of all male cancer. Among 11,543 cases of carcinoma of the breast seen at the Christie Hospital and Holt Radium Institute, Manchester, between 1945 and $1959,110(0.95 \%)$ were in males. Other records seem to show precisely the same proportion, suggesting a similar aetiological background for breast cancer in the two sexes.

Although in males there is a relation between gynaecomastia and some endocrine and hepatic disorders, no such relation has been established or noted in cancers of the male breast. Cancer of the male breast has been observed, however, in response to therapeutic oestrogen, usually administered for prostatic carcinoma (Liebegott, 1948 ; McClure and Higgins, 1951 ; Graves and Harris, 1952 ; Jakobsen, 1952). Since carcinoma of the male breast appears rather late in life, in view of the greater likelihood of adiposity at this age associated gynaecomastia may be difficult to recognize.

* Christie Hospital and Holt Radium Institute, Manchester. + Paterson Laboratories, Manchester.

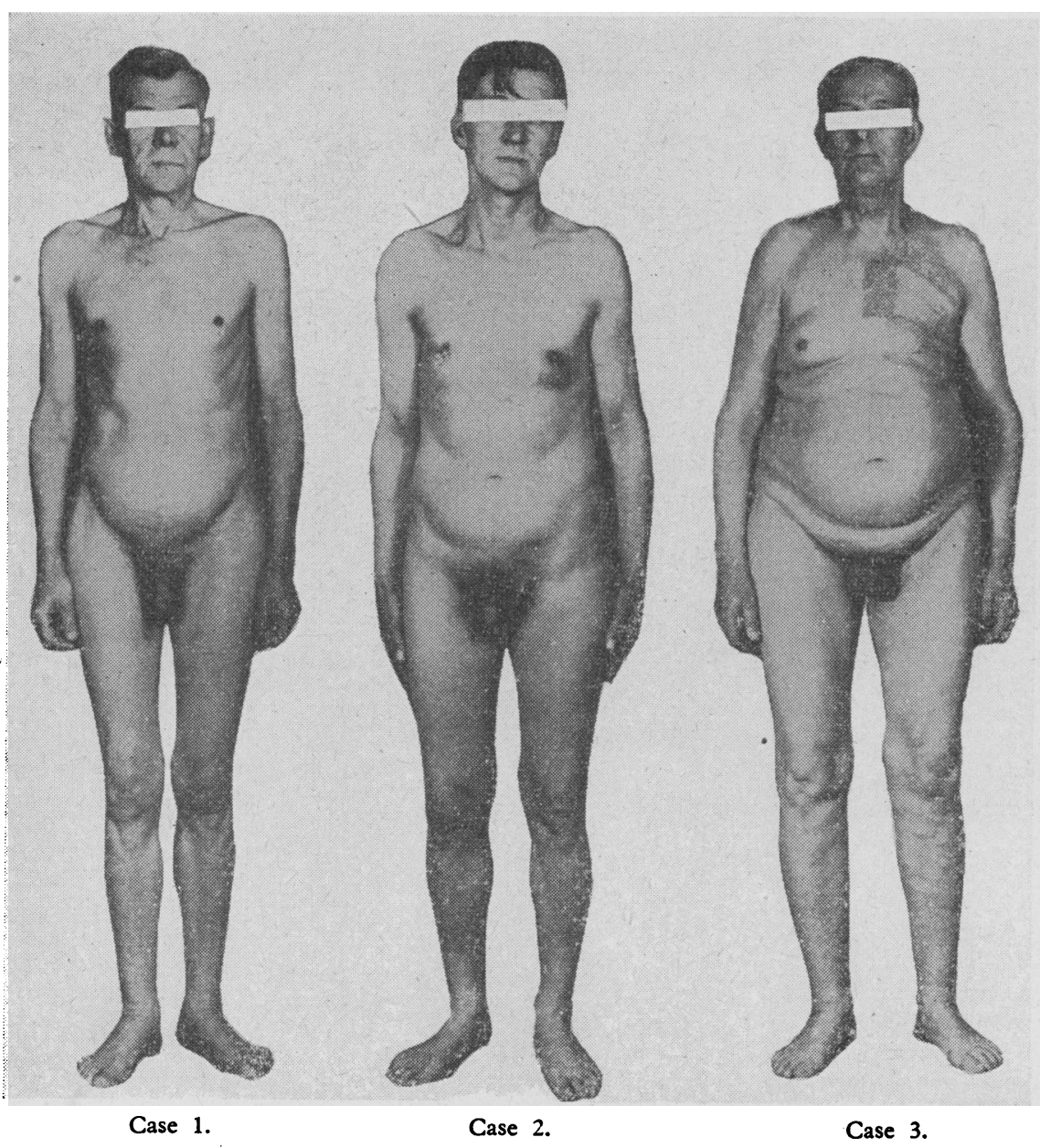

FIG. 1.-Photographs of the three patients.
Recently breast carcinoma was observed in a 59-year-old man who also had extremely small testes. A preliminary investigation of the nearest available patients with male breast carcinoma who are on follow-up at the present time, a total of 21 patients, showed three cases of chromatin-positive buccal smears. Although, as is demonstrated below, all three proved to have the Klinefelter syndrome (K.S.), none were clinically outstanding or typical examples of K.S. when viewed against the background of these breast-cancer males.

The K.S. (Klinefelter et al., 1942) is characterized by testicular hypoplasia, aspermia, slight development of secondary sex characters, gynaecomastia, and increased secretion of urinary gonadotrophin. The degree of gynaecomastia is inversely correlated with the eunuchoid features (Heller and Nelson, 1945), so that the more masculine type should present the most noticeable gynaecomastia.

The incidence of K.S. in males is given as $1: 1,000$ (Prader et al., 1958) to 1:400 (Moore, 1959), based on the presence of sex chromatin in buccal smears. Ferguson-Smith et al. (1957) distinguished chromatin-negative and chromatin-positive "types" of K.S., each with distinctive testicular morphology.

The present communication deals with the three chromatin-positive males among 21 male breast-cancer patients (Fig. 1), representing more than half of the total number of male cases on follow-up at the Christie Hospital and Holt Radium Institute, Manchester.

\section{Case Histories}

Case 1.-A 59-year-old man of average intelligence. Married at 25 and divorced 12 years later. No children. Six months' history of a swelling in the right breast. First seen (5 February 1963) with a stage III carcinoma of the right breast and treated initially by radical radiotherapy. The tumour recurred locally, however, and radical mastectomy was performed: he remained well three months after operation. Histology: Adenocarcinoma with axillary lymph-node involvement. Previous medical history: Very severe chronic bronchitis for 10 years ; left inguinal hernia present for an unspecified period; partial gastrectomy for duodenal ulcer 10 years previously. Family history: No history of breast cancer; four married brothers with children.

Case 2.-A 52-year-old man of average intelligence. Married at 29. A child was adopted after seven years of marriage. Two months' history of crusting of the right nipple. First seen (5 December 1962) with a stage III carcinoma of the right breast and treated initially by radical radiotherapy. Five months later contralateral supraclavicular and axillary nodes were involved and bone metastases developed, which did not respond to palliative radiotherapy or hormone therapy (stilboestrol $20 \mathrm{mg}$. daily). This drug was discontinued after six months and the patient has been referred for consideration of adrenalectomy. Histology :-Biopsy of metastatic nodule: 
“ scirrhous adenocarcinoma of mammary type." Previous medical history: Left inguinal hernia present for 12 years. Family history: No history of breast cancer; no siblings.

Case 3.-A 55-year-old man of average intelligence. Married at 26 and claims a daughter aged 24 years. Referred (12 June 1957) after local mastectomy for a swelling in the breast associated with nipple retraction. Post-operatively he was taking stilboestrol $45 \mathrm{mg}$. daily. Radical radiotherapy was given and the stilboestrol was discontinued three years later, when gynaecomastia became troublesome. He remained well seven years after operation. Histology: "Duct carcinoma." Previous medical history: Bilateral inguinal hernia present for 10 years. Family history: No history of breast cancer; a sister died in infancy and a brother is married, with children.

\section{Investigations}

A summary of the clinical findings is given in Table I. The results of hormone assays are shown in Table II. The total gonadotrophins were measured by the method of Loraine and Brown (1959).

TABLE I.-Summary of Clinical Findings

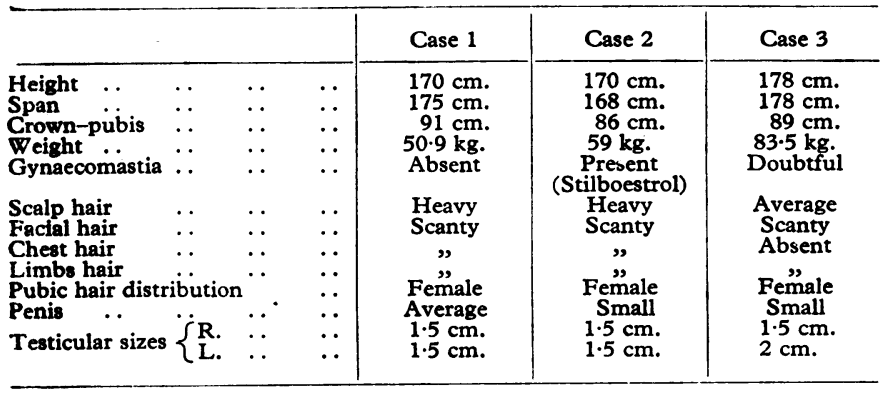

TABLE II.-Hormone Assays

\begin{tabular}{|c|c|c|c|c|}
\hline & & Case 1 & Case 2 & Case 3 \\
\hline $\begin{array}{l}\text { 17-ketosteroids (mg. } / 24 \mathrm{hr} \text { ) } \\
\text { 17-ketogenic steroids (mg./24 } \mathrm{hr} .) \quad \cdots \\
\text { Gonadotrophins (mg. } / 24 \mathrm{hr} .)(\mathrm{HMG}-1)\end{array}$ & $\begin{array}{l}\cdots \\
\cdots\end{array}$ & $\begin{array}{c}9 \cdot 1 \\
6 \cdot 4 \\
63 \cdot 5 \\
\text { (high) }\end{array}$ & $\begin{array}{c}3 \cdot 6 \\
5 \cdot 2 \\
12 \cdot 2 \\
\text { (normal) }\end{array}$ & $\begin{array}{c}12 \cdot 2 \\
17 \cdot 2 \\
6 \cdot 4 \\
\text { (normal) }\end{array}$ \\
\hline
\end{tabular}

Chromosome Investigations.-Giemsa- and Leishman-stained blood smears were examined for "drumsticks" in neutrophil leucocytes (Davidson and Smith, 1954). Cases 1 and 2 had about $3 \%$ (as in normal females), but Case 3 was indecisive. No attempt was made at concentrating the leucocytes (De $\mathrm{La}$ Chapelle et al., 1964). Buccal smears were stained with cresyl violet and gave the sex-chromatin incidence shown in Table III.

TABLE III

\begin{tabular}{|c|c|c|c|c|c|c|c|c|}
\hline & & & & & \multicolumn{4}{|c|}{ No. of Barr Bodies } \\
\hline & & & & & 0 & 1 & 2 & \\
\hline $\begin{array}{l}\text { Case } 1 \\
\text { Case } 2 \\
\text { Case } 3\end{array}$ & $\begin{array}{l}\ldots \\
\ldots\end{array}$ & $\begin{array}{l}\cdots \\
\cdots\end{array}$ & $\begin{array}{l}\cdots \\
\cdots\end{array}$ & $\begin{array}{l}\ddot{ } \\
\therefore\end{array}$ & $\begin{array}{l}60 \\
56 \\
57\end{array}$ & $\begin{array}{l}40 \\
44 \\
42\end{array}$ & 1 & $\begin{array}{l}100 \% \\
" " \\
"\end{array}$ \\
\hline
\end{tabular}

Although blood samples were taken from all three cases, the leucocyte cultures did not prove as valuable for chromosome studies as the subsequently established skin cultures. Although a larger number of cells were chromosome-counted, variation due to technical reasons makes it most convenient to consider only the completely analysed cells (Table IV). From a score of over 100 cells it was concluded that Case 3 was a mosaic with three stemlines, $\mathrm{XY} / \mathrm{XXY} / \mathrm{XXXY}$; and that Cases 1 and 2 were of the standard Klinefelter type, XXY (Figs. 2-4). $\mathrm{H}^{3}$-thymidine labelling was carried out and will be reported on elsewhere.

1 On pathological review the malignant nature of this specimen has been queried.

\section{Discussion}

Although no testicular biopsies have been taken, the chromosome findings must be considered as sufficiently conclusive for the diagnosis of K.S. Case 3 has an unusually low gonadotrophin level, which perhaps is explained by his mosaicism. Whether this also can explain his apparent fertility remains to be seen.

There were three Klinefelter males and 18 non-Klinefelter males in the present sample. Even with the highest estimated incidence of K.S. in the male population $(1: 400)$, the incidence of breast cancer associated with this syndrome is 66.5 times higher than in non-Klinefelter males.

So far as we know at present the incidence of K.S. is not dependent upon the age of a population sample as is the case with incidence estimates of breast cancer. The peak incidence of breast cancer in males is found in their 63rd year (Christie Hospital series), and this age-group represents $0.9 \%$ of the male population. The peak incidence in females is in their 58th year (Harnett, 1948) (and two years earlier in spinsters who have a slightly higher incidence than married women), and this age-group constitutes $1.16 \%$ of the female population.

\begin{tabular}{|c|c|c|c|c|c|c|c|}
\hline & & \multicolumn{6}{|c|}{ Chromosome Numbers* } \\
\hline & & 45 & 46 & 47 & 48 & 94 & Total \\
\hline $\begin{array}{l}\text { Case } 1 \\
\text { Case } 2 \\
\text { Case } 3 . .\end{array}$ & $\begin{array}{ll}\ldots & \ldots \\
\cdots & \ldots\end{array}$ & 2 & $\begin{array}{l}1 \\
1 \\
7\end{array}$ & $\begin{array}{l}28 \\
27 \\
40\end{array}$ & 3 & 1 & $\begin{array}{l}30 \\
28 \\
52\end{array}$ \\
\hline
\end{tabular}

* Only cells deviating in group III are given.

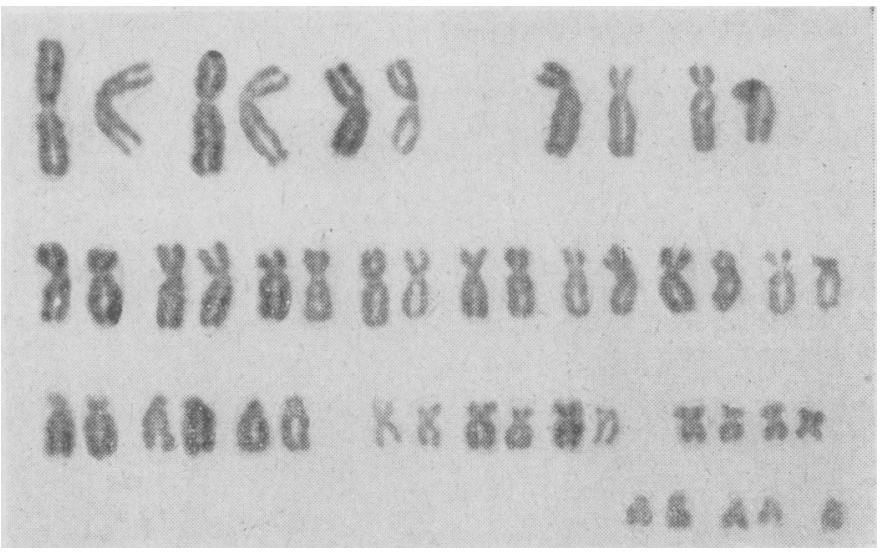

FIG. 2.-Case 1. Karyotype with 47 chromosomes and sex-chromosome constitution XXY.

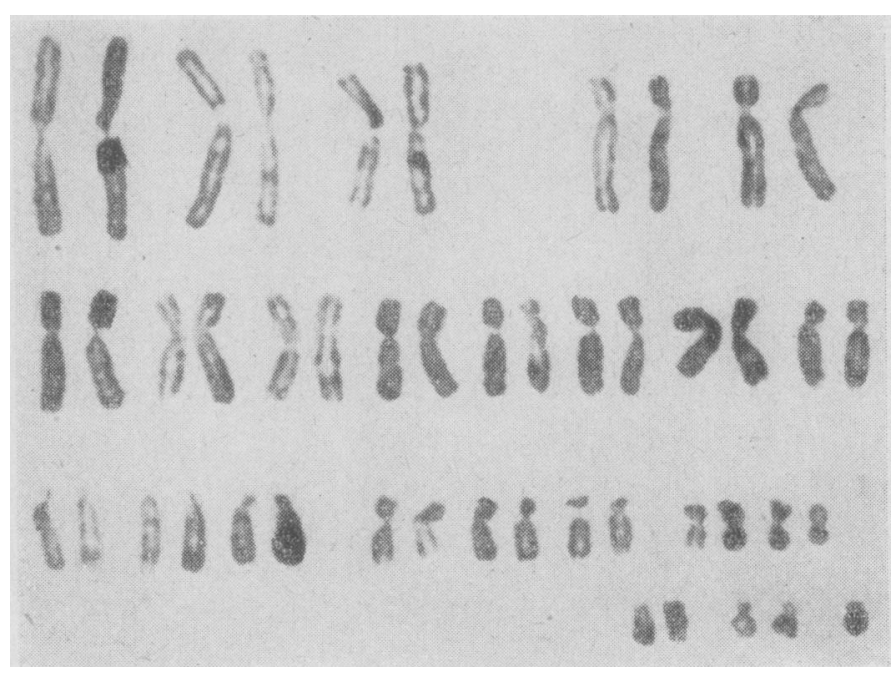

FIG. 3.-Case 2. Karyotype with 47 chromosomes and sex-chromosome constitution XXY. 
Applying these figures to the South-Western Cancer Registry, 1961, gives the following rough estimate of breast cancer:

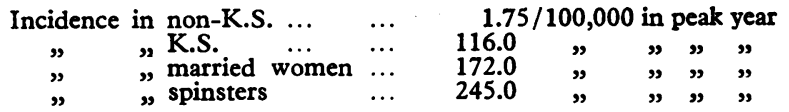

These data can only be approximate estimates, but they make it clear that the incidence of breast cancer in males with the K.S. is of about the same order as that for women.

It would seem that some aetiological relationship may exist between the K.S. and the development of breast cancer in such males. Most probably this is related to the abnormal hormone status associated with the syndrome. It would be reasonable to suppose that the hormone status is related to the genetic constitution-and the sex chromosome constitution in particular. It is commonly found that K.S. males have a low or low-normal 17-ketosteroid excretion and a raised pituitary gonadotrophin level. These two factors are not well correlated, however, and the increased gonadotrophin level is by far the most characteristic finding in K.S: males.

Apart from the slightly lower level in normal females compared with males, the gonadotrophin level increases tenfold in normal females after the menopause; a similar high level is

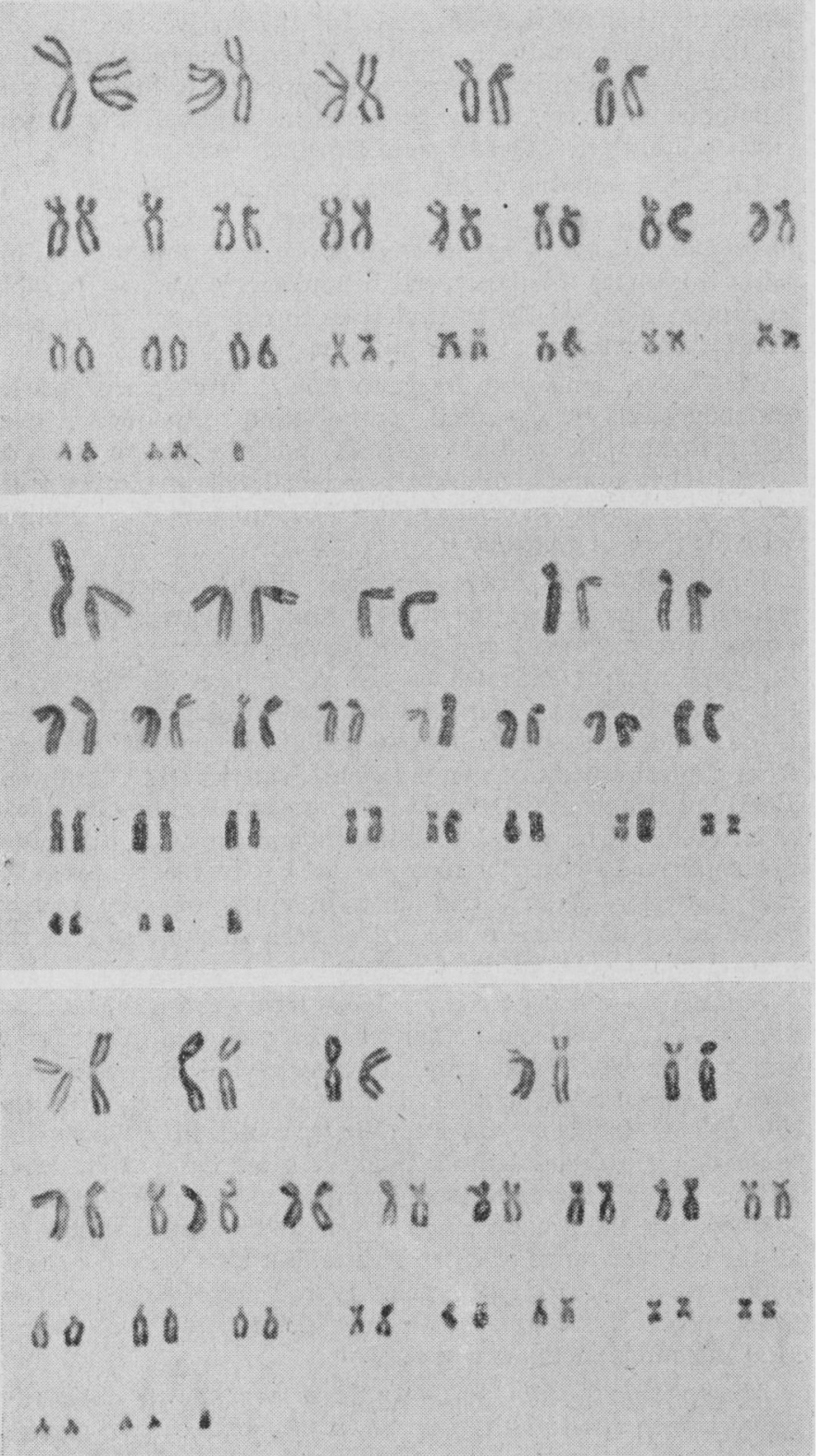

FIG. 4.-Case 3. Cells representing the three stemlines $46-\mathrm{XY}, 47-\mathrm{XXY}$, and $48-\mathrm{XXXY}$. found in males with gonadal agenesis (unspecified) and the average level in Klinefelter males is claimed to be not as high (Johnsen, 1964). It has recently been suggested that the inhibitor feed-back mechanism from the testes to the hypophysis is dependent upon the apocrine secretion from the spermatids during spermatozoogenesis (Johnsen, 1964). This could bring other factors than sex-chromosome constitution into consideration, factors which impair or inhibit meiosisnamely, cryptorchidism and testicular disease-or hinder the feedback mechanism itself-namely, obstruction of vas by trauma or hernia.

In recent years much stress has been laid on the possible importance of oestrogens in the aetiology of breast cancer, and, of course, this factor cannot be excluded in cases of female breast cancer where the normal high cyclic levels of oestrogens may be present for a great part of adult life. It is important, therefore, to exclude the possibility of raised oestrogen levels inducing breast cancer in K.S. males. Unfortunately, facilities were not available to carry out this assay on the patients described. However, Heller and Nelson (1945) reported normal levels in their series of K.S. males, and this was confirmed by Giorgi and Sommerville (1963), who found that the oestrogen levels in K.S. males were slightly lower than the normal. On these grounds it seems unlikely that this factor is of major importance.

In the light of recent work on the importance of androgens in the problem of female breast cancer (Bulbrook et al., 1964) it may well be that this factor also is of some importance in male breast cancer, and more particularly in the low-androgen K.S. males.

Since the incidence of the K.S. is unlikely to differ from one area to another, the demonstration of a constant proportion of Klinefelter males of all breast-cancer cases would greatly strengthen the likelihood of excluding external factors (infection, etc.) from the general aetiology of breast cancer.

The concept of a genetic background to breast cancer is of course strengthened by this finding. The similarity of the incidence among K.S. and normal females suggests a similarity in aetiology. Breast lesions in patients with the K.S. should receive the same care and inspection as in female patients. It is also to be hoped that the isolation of this group among male breast carcinoma will give opportunities for an increased understanding of this type of malignancy, as well as making a differential therapy possible.

\section{Summary}

Three cases of chromatin-positive Klinefelter syndrome in association with carcinoma of the male breast are described. Chromosome studies are reported in these patients. The approximate incidence of breast carcinoma in the Klinefelter syndrome is calculated, and is shown to be of the same order as the incidence in women. Possible aetiological factors are discussed.

\section{REPERENCES}

Bulbrook, R. D., Hayward, J. L., and Thomas, B. S. (1964). Lancet, 1, 945.

Davidson, W. M., and Smith, D. R. (1954). Brit. med. F., 2, 6.

De La Chapelle, A., Hortling, H., Niemi, M., and Wennström, J. (1964). Acta med. scand., 175, Suppl. No. 412, p. 25.

Ferguson-Smith, M. A., Lennox, B., Mack, W. S., and Stewart, J. S. S. (1957). Lancet, 2, 167.

Giorgi, E. P., and Sommerville, I. F. (1963). F. clin. Endocr., 23, 197.

Graves, G. Y., and Harris, H. S. (1952). Amer. Surgn., 135, 411.

Harnett, W. L. (1948). Brit. F. Cancer, 2, 212.

Heller, C. G., and Nelson, W. O. (1945).' F. clin. Endocr., 5, 1.

Jakobsen, A. H. I. (1952). Acta path. microbiol. scand., 31, 61.

Johnsen, S. G. (1964). Acta endocr. (Kbh.), Suppl. No. 90, p. 99.

Klinefelter, H. F., Reifenstein, E. C., jun., and Albright, F. (1942). f. clin. Endocr., 2, 615.

Liebegott, G. (1948). Klin. Wschr., 26, 599.

McClure, J. A., and Higgins, C. C. (1951). f. Amer. med. Ass., 146, 7.

Monre. K. L. (19)9). Lani et, 1, 217.

Prader, A., Schneider, J., Francés, J. M., and Züblin, W. (1958). Ibid., 1, 968. 